\title{
DISRUPTIVE TECHNOLOGY INNOVATION FOR NUTRITION
}

\section{A SUMMARY REPORT OF A MEETING}

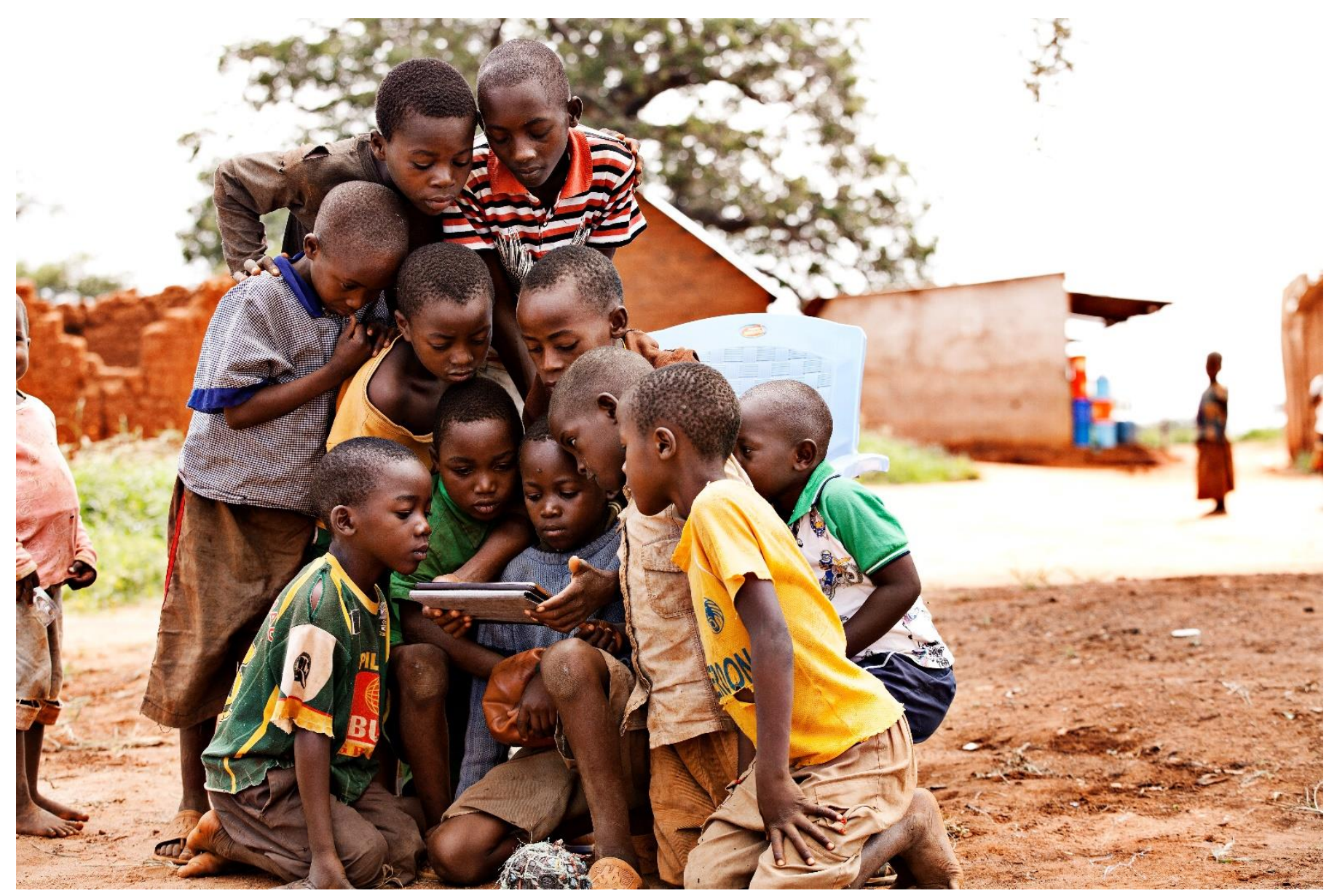

GAIN Convening Paper Series n5

September, 2019

Charlotte Pedersen, Sharada Keats, Catrin Kissick 


\section{ABOUT GAIN}

The Global Alliance for Improved Nutrition (GAIN) is a Swiss-based foundation launched the UN in 2002 to tackle the human suffering caused by malnutrition. Working with governments, businesses and civil society, we aim to transform food systems so that they deliver more nutritious food for all people, especially the most vulnerable.

\section{Recommended citation}

Pederson C, Keats S, and Kissick C. Disruptive Technology Innovation for Nutrition. Global Alliance for Improved Nutrition (GAIN). Convening Paper Series \#5. Geneva, Switzerland, year. DOI: https://doi.org/10.36072/cp.5

\section{(C) The Global Alliance for Improved Nutrition (GAIN)}

This work is available under the Creative Commons Attribution-Non-Commercial-Share Alike 4.0 IGO licence (CC BY-NC-SA 4.0 IGO; https://creativecommons.org/licenses/by-nc-sa/4.0/). Under the terms of this licence, you may copy, redistribute and adapt the work for non-commercial purposes, provided the work is appropriately cited, as indicated below. In any use of this work, there should be no suggestion that GAIN endorses any specific organisation, products or services. The use of the GAIN logo is not permitted. If you adapt the work, then you must license your work under the same or equivalent Creative Commons license. The contributions of third parties do not necessarily represent the view or opinion of GAIN.

\section{Acknowledgements}

Thank you to Bluetown for providing the use of the photograph in this convening paper. All photographs included in this document have been taken with consent for use in publications.

\section{GAIN CONVENING PAPER SERIES}

The GAIN Convening Paper Series brings together proceedings and reports from events that have been convened or co-convened by GAIN.

The Global Alliance for Improved Nutrition (GAIN)

Rue de Varembé 7

1002 Geneva

Switzerland

T: +41227491850

E: info@gainhealth.org

www.gainhealth.org 


\section{SUMMARY}

Malnutrition in all its forms has devastating impacts on individuals and communities across the globe, affecting children's health and cognitive development, health throughout the life course, and nations' economic prosperity. Current food systems are unable to address this burden of malnutrition, as they cannot provide safe, nutritious foods for all. Transforming them to do so requires innovation. GAIN, as part of its Project Disrupt, thus hosted a roundtable meeting in London on 17 June 2019 to engage twenty innovation experts from diverse sectors to explore how large-scale technological innovations might be harnessed to drive improvements in nutrition. This report summarises the result of that meeting.

\section{KEY MESSAGES}

- Diverse innovations from technology and finance have the potential to be deployed and drive improvements in nutrition outcomes.

- GAIN thus brought together experts from these fields to discuss six key themes: megatrends, supply chains, industrial architecture, consumer demand, investment for innovation, and the role of governments.

- These innovation experts identified areas where major gains in high-technological advancement could benefit nutrition outcomes, including improving connectivity for the "last billion".

- As a result of this meeting, GAIN has engaged with two organisations represented at the roundtable to discuss potential partnerships for better nutrition for all. 


\section{BACKGROUND AND OBJECTIVE}

Malnutrition is a major problem across many parts of the world, leading to poorer outcomes in infants and children and health problems throughout life, which reduce economic growth and quality of life. Many of the causes of malnutrition have to do with diets, and diets are shaped by the food system - the actors and activities involved with the production, processing, transport, and consumption of food and the policies that influence them. Current food systems across much of the world, particularly in low- and middle-income countries (LMICs), are failing to deliver nutritious diets. They do not provide safe, nutritious foods that are affordable and accessible to all consumers, particularly the most vulnerable; they also often have negative environmental impacts.

Interventions focused only on nutrition cannot solve these wide-ranging problems in the food system. Instead, addressing malnutrition will require systemic transformation. The world has witnessed the transformative power of modern large-scale high-tech innovations, such as mobile technology and the widespread adoption of the internet, with billions of individuals reached. However, the worlds of large-scale technological innovation and nutrition rarely interact.

GAIN, a leader in public-private engagement for better nutrition, recently published Nutritious Food Foresight, which highlights 12 feasible innovations for better nutrition in emerging markets. However, GAIN has limited experience in large-scale innovations outside the agriculture and nutrition spheres. GAIN thus sought to engage with technology experts and explore how current trends and innovations might have the potential to improve diets. This was done through a roundtable meeting that brought together experts from the technology and finance industries to shed light on how to exploit new ideas and technologies to nourish and feed a growing world, in a sustainable way. This paper summarises that meeting.

\section{OVERVIEW OF THE MEETING}

The meeting, held in London on 17 June 2019 as part of GAIN's Project Disrupt, aimed to bring together industry experts to discuss the latest trends in the areas of connectivity, digital identity, artificial intelligence, big data, platforms, marketplaces, social content, public policy, and digital literacy.

The purpose of the meeting was twofold:

1) to engage and inform industry experts of the challenges of malnutrition; and

2) to explore how innovations outside the nutrition sphere could benefit nutrition outcomes.

Twenty stakeholders from the technology and finance sectors, many of whom had not met before, joined the meeting. GAIN informed these industry leaders of the burden and consequences of malnutrition, while encouraging them to identify potential innovations that might be deployed to directly or indirectly improve nutrition outcomes. Roundtable discussions sought to explore the extent to which the trends mentioned above could bring 
about improvements in diets. The discussion was framed in terms of seeking either hard (technological) or soft(non-technological), high- or low-technological innovations that could transform the food system to deliver safe and nutritious foods for all; technological innovations can be either high-tech (i.e., complex or cutting-edge) or low-tech (i.e., simple, traditional or non-mechanical). The annex to this report lists types of innovations referenced during the roundtable discussions. The meeting was held under Chatham House Rules: individuals presented their own views, rather than those of their organisations.

The meeting covered six key themes. Within each, participants provided an overview of the current trends, opportunities, and challenges, while identifying where GAIN could bridge the gap between the nutrition sector and the tech industry. The following sections summarise the main outcomes of these discussions, by theme.

\section{MEGATRENDS}

The discussion of megatrends highlighted that rapid increases in connectivity (mobile networks and the Internet of Things (IOT)) ${ }^{1}$ have led to exponential growth in data and information. This data, combined with new processing capabilities (e.g., artificial intelligence (Al) and machine learning) are providing access to more accurate, lower-cost information to inform decisions within a wide range of systems and processes. Governments in LMICs are investing heavily in digital capabilities, closing the digital divide. This is often happening rapidly in settings without legacy systems to replace, such as how mobile phones have obviated the need for landlines in many LMICs.

\section{SUPPLY CHAINS}

The experts claimed that increasing availability, access, and use of data will help to level the playing field between supply chain actors. In some cases, production is taking place closer to consumption (reducing costs), with mass personalisation (increasing desirability) enabled by innovations in transportation and production. New production opportunities are being created nearer the customer (e.g., vertical farming, customised production, and automated vendors). Marketplaces are facilitating shortening and de-centralising of supply chains. Automation, driven by ever-decreasing hardware costs and connectivity-driven intelligence, is providing more alternatives to human labour, as well as new production capabilities. Implementing such solutions require the core capabilities of a digital economy, including high levels of digital literacy and identity, financial inclusion, information access, effective marketplaces, and local content.

\section{INDUSTRIAL ARCHITECHTURE}

The group discussed how connectivity can facilitate social and economic systems. Penetration is lower (with less than 35\% of the population having internet access) in low-income countries,

\footnotetext{
${ }^{1}$ The Internet of Things (loT) is a system of related machines, objects, animals, and people that has the ability to transfer data and execute operations without human command.
} 
but it is accelerating quickly. Despite great progress, connectivity will remain a challenge in very rural areas. This has implications for financial inclusion, which drives increased economic participation and is enabled by digital technologies. Widespread financial inclusion requires a combination of on-line architecture and comprehensive off-line distribution networks.

New marketplaces (such as Amazon, Flipkart, and Alibaba) are providing low-cost ways to access very large audiences. Combined with advanced distribution and payment systems, they provide compelling customer propositions (in terms of speed, choice, cost, and accessibility). These marketplaces collect and use large amounts of customer data in order to become increasingly competitive. Distribution networks are also becoming more agile, allowing decisions to be made at shorter notice and closer to the customer.

Digitised information is enhancing the prediction power of suppliers, enabling production or processing closer to consumption (thereby reducing the length of the 'last mile'), and liberating private transportation (through platforms like Ola, Uber, and Lyft). These forces combine powerfully to create more direct business-to-consumer channels, rather than consumers collecting goods from business. Ultimately, experts see automated transportation of goods becoming cheaper (or at least more efficient, given the cost of labour and premises) to the extent that fleets of autonomous vehicles (cars, bikes, and drones) will deliver all types of goods, including low-cost and perishable items. These distribution models and new marketplaces reward their shareholders but also have negative externalities. Many rely on monopolistic models, insecure or exploitative labour, and tax avoidance that facilitate undercutting local small enterprises.

\section{CONSUMER DEMAND}

The internet facilitates access to global content and can widen the range of consumer influences. However, content is often homogenised (as is most cost effective) and created in limited languages. It is local content that is often the most valuable. The group highlighted that inspiration (rather than education) is the language of influence in digital communication. Increasingly, that influence is being expressed through imagery (video in particular).

Online retailing has created a small number of global giants - margins are low, so scale counts. These combine with a very long tail of niche players. Scale requires building large customer bases and encouraging customer loyalty (and frequency of purchase). 'Gamification' is a critical concept in audience building and retention. It involves assembling and activating several automated psychological cues to create frequent instincts to engage, persist, and progress through a process. These cues include: incentives, rewards, achievement, recognition, progress, and the creation of a desire to be involved or a fear of 'missing out.'

Subscription models are often favoured, as they formally secure the relationship with a consumer, which often remains in place longer and generates more life-time value than competing for individual transactions. Financial incentives remain critical, especially in lowincome markets. It is critical to offer lower prices or special offers to change consumption patterns. This is so far unchanged by digital services or the added-value experience they offer. For example, 'freemium' product offerings, two-sided business models (wholesale data with a retail product), lean, low-capital operating models, and even forgoing profit to build 
market share are all established methods of enabling this.

All of these trends could have implications for nutrition and foods choice, and many experiments are being conducted in encouraging consumer behaviours in this space, such as digital vouchers for specific food groups in Sierra Leone. However, providers must be wary of unintended consequences, like distortion of other eating behaviours, or opportunities provided for coercion, fraud, and other criminality.

The experts also highlighted that online consumer engagement only works so far. Physical distribution networks are essential to facilitate trust and create an interface between the virtual and real worlds. For example, mobile money growth requires thousands of agents geographically dispersed; transport needs thousands of cars and, currently, drivers. The group also noted that, as personal financial management becomes digitised, lowering the friction of transactions, individuals' relationships with money are expected to evolve — with broad implications for consumer behaviour.

\section{INVESTMENT AND INNOVATION}

Innovation often requires financial investment. The experts discussed how communications and network services require substantial upfront investments of different kinds. Networks require very large investments in capital and licenses. Internet services require innovation capital, investing in many ventures to identify the few successes, followed by heavy investment in successes to establish them in the mass market. Developing markets, with lower income levels, GDP, and financial liquidity, do not present the financial incentives for comprehensive investment. From a longer-term perspective, these markets will surely merit investment and drive innovations, but the absence of short-term returns (either in income or exit strategy) is hampering substantial investment.

Moreover, formal financial institutions do not normally provide the relatively small levels of investment required to stimulate early-stage innovators in the food sector. New models need to be explored. These may include shared risk between the public and private sectors; state underwriting or limiting losses; or finding ways to tap into different sources of start-up investment (e.g. crowd-funding, investor matching). Governments in many markets, especially LMICs, view technology-enabled services as an opportunity for short-term taxation revenue rather than long-term infrastructure building. This is slowing down technology investment, especially in the lowest-income markets.

\section{ROLE OF GOVERNMENTS}

Governments play fundamental roles in determining the level of technology infrastructure available and in facilitating technology adoption. Impactful policies include taxation (from luxury to public utility), corporate investment incentives, investing in education, encouraging entrepreneurship, and making venture investments. Governments also (and increasingly) play a fundamental role in protecting citizens, society, and national security from the (typically unintended) negative externalities of internet-based services. In LMICs, governments wishing to accelerate technology adoption may need to play a role in incentivising or de-risking 
investment. For example, by reducing the cost of spectrum ${ }^{2}$ or incentivising investment in rural communication networks and by underwriting risk or creating liquidity channels for earlystage investors.

The global nature of many internet services requires a supra-national approach to regulation: cross-government collaboration is recommended. Governments may leverage (or be affected by) digital services in the provision of public services; citizenship, democratic services, education, health, welfare, and payments can all be transformed in their cost, effectiveness, and reach.

\section{MOVING FORWARD}

This first meeting was a chance for sectors that rarely have an opportunity to meet to informally exchange ideas. GAIN sought to explore how to inspire those in the innovation industry to engage with the challenges of malnutrition while learning from and looking for opportunities to leverage innovation experts' knowledge to improve nutrition programming. GAIN hopes to incorporate the new knowledge gleaned from the meeting into future innovative workstreams. Several of the stakeholders from the technology and finance industries involved expressed an interest in remaining informed of GAIN's work, as well as in exploring opportunities for future collaboration to drive the agenda of better nutrition for all.

2 the radio frequencies allocated to the mobile industry and other sectors for communication over the airwave 


\section{ANNEX: EXAMPLES OF FOOD SECTOR TECHNOLOGIES DISCUSSED}

Agroknow - A company providing digital science innovation in agriculture, food, and water.

Apeel sciences - A firm that uses food to preserve food. For example, they apply a coating to fresh fruit and vegetables that significantly extends shelf life.

blueMoon Ethiopia - A start-up to support other Ethiopian start-ups in the food and agricultural space.

BlueTown - A company offering wifi solutions to connect people in rural areas of the world.

esoko - A firm that provides market prices via text message to smallholder farmers through development projects, with the aim of using the emergence of mobile technology in Africa to improve the lives of rural communities across the continent.

FSD Africa - An organisation funded by DFID to reduce poverty through financial sector development.

Jio phone - A new smartphone from India, run on the (KaiOS) operating system, similar to Android. As devices cost just $\$ 20$, it could enable another billion people to have smartphones.

makarfid - A manufacturer and exporter of high-quality radio-frequency identification (RFID) products along with technology services, including tags, labels, card, antennas, readers, and customised services.

plantix - A company that connects farmers in India to one another through SMS.

Waze - A mobile phone application that, through rapid growth, became the default map in Israel. Users get points for driving on roads they have not travelled before, offering a good example of incentivising and gathering information from users.

wefarm - A company that connects farmers in Africa to one another through SMS. 